JISTEM - Journal of Information Systems and Technology Management

Revista de Gestão da Tecnologia e Sistemas de Informação

Vol. 11, No. 1, Jan/Apr., 2014 , pp. 21-32

ISSN online: $1807-1775$

DOI: $10.4301 / \mathrm{S} 1807-17752014000100002$

\title{
THE FUTURE OF AUDIT
}

\section{Danielle Lombardi}

Villanova University, Pennsylvania, United States, USA

Rebecca Bloch

Fairfield University, Connecticut, United States, USA

Miklos Vasarhelyi

Rutgers University, New Jersey, Unites States, USA

\begin{abstract}
The purpose of this study is to discuss the current state and future of auditing. Expert consensus is used as a basis to examine the current state of auditing and generate modifications both needed and likely to occur in the audit profession. This study contributes to the literature by using the Delphi method to develop predictions as to the direction of the audit industry and discuss the implications associated with these predictions. If auditors can better understand where the profession stands and where it is headed, then they can better prepare for the future. Some predictions emerging from this study relative to future audit practices include increasing automation of audit procedures, more predictive financial statements, continuous auditing of financial statements and transactions, and an increasingly global perspective regarding audit activities.
\end{abstract}

Keywords: Audit; Brainstorming; Delphi method; Information systems; Expert panel

\section{INTRODUCTION}

The auditing field is at a critical juncture. Independent audits continue to take place annually, whereby associated analysis and reporting routines are based solely on historical data. With the resulting lack of timeliness between data generation and information assurance in this context, it seems that stakeholders would typically not view audited financial statements as being useful for decision-making in the current and

Manuscript first received/Recebido em 10/12/2013 Manuscript accepted/Aprovado em: 05/03/2014

Address for correspondence / Endereço para correspondência

Danielle Lombardi, Assistant Professor at the Villanova School of Business, Villanova University, 800 E. Lancaster Ave. Bartley Hall - 3048 Villanova, PA 19085, E-mail: danielle.lombardi@ villanova.edu

Rebecca Bloch, Assistant Professor at the Dolan School of Business, Fairfield University, 1073 North Benson Road, Dolan School of Business - 2109, Fairfield, CT 06824 E-mail: rbloch@ fairfield.edu

Miklos Vasarhelyi, Professor II KPMG Professor of AIS Director CarLab, RARC room 9461 , Washington Park Newark, NJ 07102 tel: 201-4544377 Rutgers University, New Jersey, Unites States, USA E-mail: miklosv@andromeda.rutgers.edu

Published by/ Publicado por: TECSI FEA USP - 2014 All rights reserved. 
evolving real-time global economy. Given that decision usefulness is a primary criterion for effective financial reporting, the need for a more timely and proactive auditing methodology is apparent. To remain relevant, auditing must take advantage of technological advances and provide assurances that are meaningful to real-time financial statement users.

This study reports on experts' consensus about the current status of the audit profession and forecasts of what the profession might resemble in a decade. Agreement about the present state of the profession was obtained through a brainstorming session and a forecast of the future was generated via the Delphi technique. This study employs a formal methodology to assess the current and future status of the audit profession, and has utility for at least two distinct groups: 1) audit professionals in helping them determine how to best structure their assurance practices, and 2) regulators in anticipating audit regulations that may be needed for audits in a real-time economy.

Audits are performed to provide assurance that financial statements properly follow current accounting standards and accurately reflect the financial position of a company. Historically, this paradigm has been useful to investors and creditors who had little information available beyond the financial statements. However, in recent years, technology has taken the lag out of conducting business such that events may be captured instantaneously, and, in some cases, markets are able to react to the constant updating of real-time information (Vasarhelyi et al. 2010). Thus, the business environment has evolved more rapidly than the audit profession (Eilifsen et al. 2001; Humphrey et al. 2009), and audited accounting information is now in a substantially disadvantaged state relative to other forms of timely information. For example, company news is readily available in the financial press and investors can differentiate between competitors by reading about product quality and other industry information posted by consumer product groups. Most important, much of this information is generated very soon after event occurrence and readily available for online consumption and processing. Auditors must be prepared and properly trained to handle the new challenges associated with collecting, processing, and incorporating new forms and large volumes of data, many of which will likely require the application and understanding of sophisticated technologies. To better clarify and address this matter, this study seeks to determine the current state of auditing and what experts believe the future auditing landscape might resemble.

The study is performed in two discrete stages: 1) a brainstorming exercise is used to determine the current state of the profession, and 2) the Delphi method is employed to obtain predictions concerning the future of auditing. The Delphi method has been suggested as a methodology that provides value and rigor to research in the fields of auditing (Garsombke and Cerrulo 1984), accounting, and accounting information systems (Worrell et al 2013), and it has been found to accurately forecast future events and trends (Bell, 1967, Mehr and Neumann1970, Dalkey and Helmer 1963, Baldwin-Morgan 1993, Holstrum et al. 1986, Brancheau et al.1996; Rowe and Wright 1999). Furthermore, it has been used extensively to predict the direction of specific industries (Melnyk et al. 2009; Ogden et al. 2005; Singh 2005; Chen 2005; Baldwin-Morgan 1993; Cegielski 2008).

The next section provides background literature and the ensuing section explains the methodology. Results and analysis are presented in the third section, and the last section contains the conclusions. 


\section{BACKGROUND}

The literature predicting changes to the audit profession can be divided into those using generic prediction efforts (Hunton and Rose 2010, Holstrum et al. 1988, Elliott 1994, 2002, Violino 2004), and papers using a formal methodology to predict specific aspects of the profession (Baldwin-Morgan 1993), rather than looking at the profession as a whole.

Elliott (1994) emphasized potential opportunities and threats within the auditing profession, specifically noting that information technology provides users with a plethora of information sources beyond the traditional financial statements, and impacts the preparation, audit, and use of financial statements. Elliot's position was that the current audit profession is threatened because audited financial statements are becoming less relevant to users such as investors, creditors, and analysts. However, he also noted that there are opportunities for the auditing profession to evolve by providing a new set of assurances on information acquired via real-time information.

Elliott (2002) recommended that the academic community study the changes needed in the assurance domain to help practitioners prepare for the future. Elliott implied that reliance on information technology (IT) may supersede the need for traditional audited financial statements, and that future users may be decision-makers beyond just investors and creditors. He noted: "Every aspect of the accounting profession is being pervasively affected by advances in information technology".

Violino (2004) discussed trends in IT audits, noting that they are "moving into the mainstream as regulatory compliance, risk management, and information security become higher corporate priorities".

Hunton and Rose (2010) argued that auditors will begin to transition from manually collecting data to managing complex decision support systems, and will thus have to become comfortable with trusting these systems.

\section{METHODOLOGY}

The methodology applied in this study was originally used at AT\&T Bell Laboratories and RAND Corporation (Bell 1967). Two rounds of brainstorming and Delphi were performed during a six-month interval, and contained some variation of expert participation between sessions. The experts in this study had in-depth backgrounds and experience in auditing and accounting, and were considered the first movers and thought leaders of the field by other audit and accounting professionals. Refer to Figure 1 for a description of the experts who participated at both sessions. 


\section{First Delphi Panel Members}

-Ex-chairman of AICPA and retired partner

- President and CEO of a Consulting Company

- President and CEO of an Advisory

Company

- Director of a Consulting Company

-Accounting Information Systems

Professor

- Accounting Professor

-Big 4 Partner in Forensics

-Big 4 Partner in Audit

\section{Second Delphi Panel Members}

-Ex-chairman of AICPA and retired partner

-Ex-executive Vice President of AICPA

-Director - New Jersey Information

Systems Audit and Control Association

- Member of Canadian Institute of

Chartered Accountants

- Database director of a company

-Accounting Information Systems

Professor

-Accounting Professor - Fellow of the

Association of Chartered Certified

Accountants

-Big 4 Partner in Forensics

Figure 1 - The Expert Participants

For a procedural overview of the brainstorming and Delphi methods performed at both sessions, refer to Figure 2 below.

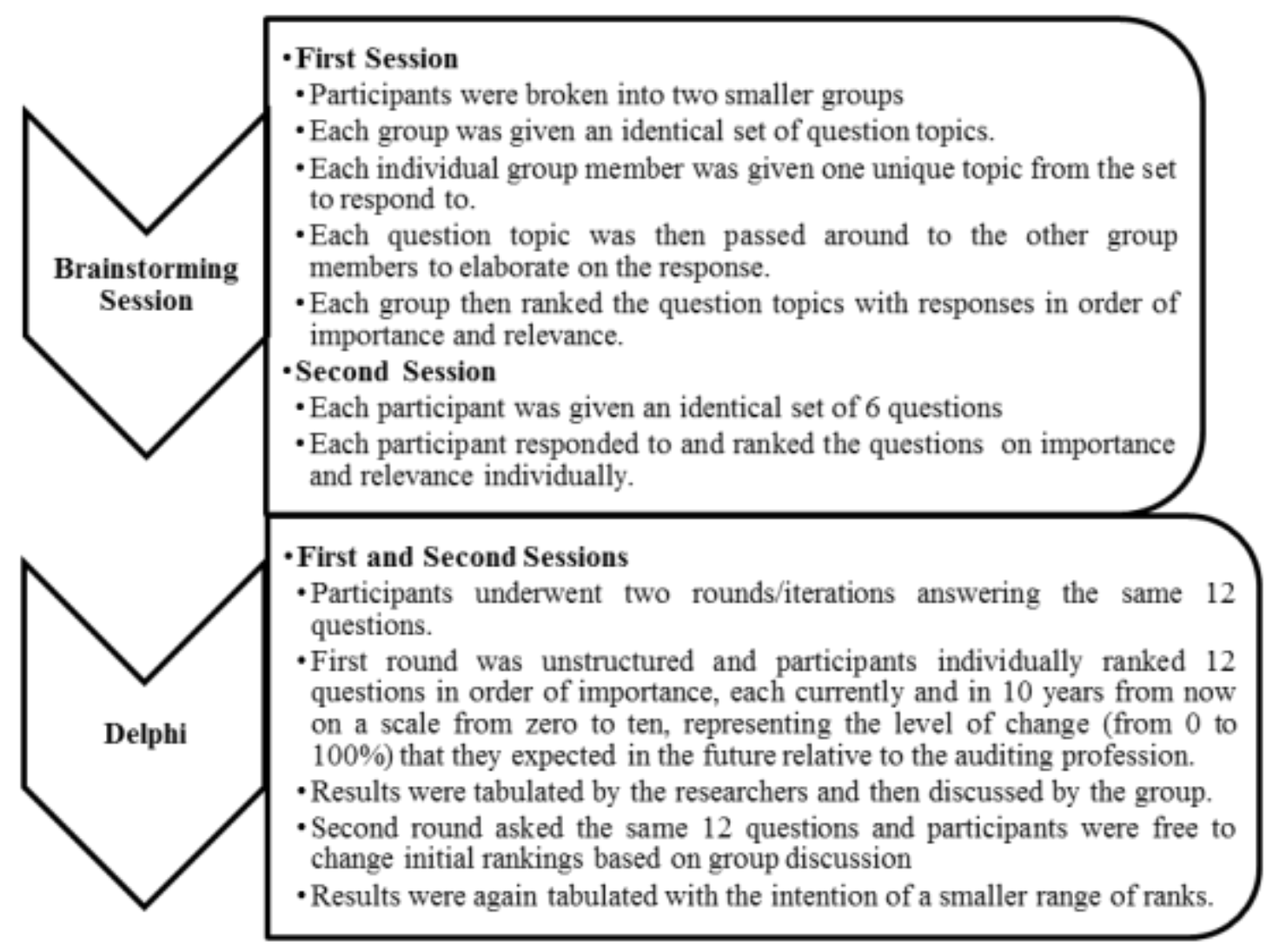

Figure 2 - The Overall Methods Used in this Study 


\section{Brainstorming Method - The Current State of Audit}

The brainstorming sessions used open-ended topics developed by a team of researchers with varied backgrounds in accounting and auditing. See Appendix 1 for brainstorming topics presented at each session.

\section{Delphi Method - The Future of Audit}

The Delphi methodology employed multiple questionnaire rounds to obtain response stability (Baldwin-Morgan 1993). Both sessions were recorded and participant discussions were transcribed to allow for a more accurate analysis and quotation of participant responses. Refer to Appendix 2 for questions asked during both Delphi sessions.

\section{RESULTS AND ANALYSIS}

The results from both sessions indicate an overall group consensus on both the current state and future of auditing. In addition, responses provided in the brainstorming method closely matched the topics of questions used during the Delphi; which provides methodological validation that the questions used in the Delphi focused on pertinent areas impacting the future of audit.

\section{Brainstorming Method Results - The Current State of Audit}

The three major areas highlighted by participants were: the audit model, technology and automation tools, and audit education.

\section{The audit model}

The audit model is evolving from traditional audits (i.e. historical data at a cutoff date) to a more continuous audit of the entire business process and associated risks, which enables current business issues to be more adequately addressed. Participants indicated that audits have changed from periodic to continuous, covering a much higher percentage of company data and monitoring of business processes. The real-time economy requires real-time assurance, and continuous auditing provides this assurance through verification and quality control. Continuous monitoring of business processes can identify emerging issues, and possibly lead to non-audit opportunities within companies. Conversely, sampling currently used in the audit process provides assurance on historical data and does not evaluate business processes.

\section{Technology and automation tools}

Automation tools, such as decision aids, currently assist auditors in analyses and risk assessments. Furthermore, these tools allow for increased usage of quantitative analyses, such as probability evaluations. As a result of increased audit automation, auditors can now spend more time reviewing analyses and interpreting results rather than performing tasks. Audit automation tools evaluate inherent risks for a particular audit, so the auditor can spend more time reviewing and interpreting analyses (rather than performing tests) and determining the desired course of action. Automated tools currently used also simulate audit procedures to determine if they are robust. Once the 
simulation procedures have been constructed, they may continually run and the auditor can reconfigure the process at any time. Some of the top technologies used currently in auditing are analytics, data bases, and sampling.

\section{Accounting education}

Accounting education has significantly progressed and now incorporates more technology, analytics, fraud detection, risk analysis, forensics, and International Financial Reporting Standards into the classroom. More electives are now available to students, as well as collaboration among courses to cover these very timely topics.

\section{Delphi Method Results - The Future of Audit}

Participant responses were examined by the researchers and paraphrased below. The paraphrasing used in this study is selective, and aims to illustrate the tone and tenor of participant discussions. Participant responses from the Delphi indicate that consensus was reached. Overall, the ranges of responses decreased round over round, with an insignificant amount of dissenters among the groups. The questions used in the Delphi sessions are shown in Appendix 2. Questions are grouped by topic to better analyze the questionnaire sessions from both Delphi meetings.

\section{Audit automation, procedures, and judgment $(Q 1 \rightarrow Q 5)$}

The overall consensus was that auditing is judgmental in nature, and, although automation can support the judgment process, it cannot replace human judgment. P3 said "Technology should reduce the barriers and repetitiveness of time-consuming sampling. We can leverage technology to get greater coverage on some areas than what we currently are doing. However, you never can automate the human judgment component. It is a part of auditing and I don't know that we want that to be automated." The use of automation also varies with company type and size, with larger companies driving the use of technology in their organizations and internal audit departments.

Judgment is also needed in the audit process to ensure that what was recorded by the system appropriately represents the actual occurrence. "I have to be able to change the lens that I am looking through because I know that people will end up sensing a pattern and their behavior will either change or stay consistent with the pattern" (P3). P1 agreed, "The firm is supposed to capture what happens in the real world in their information system. The most important issue for auditors is whether what happened in the real world is reflected in the client's and I don't think this can be 100 percent automated."

"Judgment and expertise" are contingent on each other, meaning expertise is required to make a quality judgment (Mock et al. 1993). Overall, participants foresee auditor judgment in conjunction with automation as essential components of the future audit. "Judgment is something that comes with experience and training. It is driven by the use of technology. Ten years from now, more and more things are going to be automated. For what we use to sit down and analyze there will be different tools to do the analytics so you can use your judgment in a different way" (P4).

To keep up with technology, more frequent auditor training will be needed, which will impose additional costs and the need for staff availability for training. Although newer staff has less experience than veteran staff, they tend to be more up-to- 
date on technology and software because experienced staff might often not receive the necessary training.

The continuing advancement of technologies is leading to a better evaluation of audit evidence. Auditors will be able to use sensors, biometrics, voice recognition, meta-information exchange, clustering, and expert systems to evaluate clients and analyze relationships among companies. A meta-information exchange will be developed from data to efficiently and effectively examine relationships among similar companies. This includes capabilities to drill down for more detailed information. Through the use of these emergent technologies, data will be delivered straight to auditors' desktops and inconsistencies will be easily identified.

Last, the use of electronic reporting, eXtensible Business Reporting Language (XBRL), may serve to expedite and improve certain audit functions, such as benchmarking and analytical review. XBRL data allows auditors to examine risks across clients in similar industries, resulting in an overall meta-analysis. This information can be provided repetitively and instantly impounded into analytic models. In addition, XBRL allows various levels of data to be tagged and subsequently used in customized reports to analyze and compare different industries and companies. These aggregation techniques allow for the combination of qualitative and quantitative data as well as historical and real-time data for a dynamic assessment including probabilities for fraud or potential error. Furthermore, these techniques allow for a more flexible, customized audit plan and a better audit by exception.

\section{Internal auditors taking over some functions from external auditors $(Q 6, Q 7)$}

The participants discussed a shift in the role of internal audit resulting from demands of end-users and regulatory bodies. For example, when the Sarbanes-Oxley Act was enacted, companies did not want external auditors doing non-audit-type work that was required by the new regulation. Currently, audit firms are more aggressive about maintaining this work, and some entities are either providing the services for free or steeply discounting them to keep other firms out. It is still unclear to the participants how this will ultimately be handled in the future.

The participants did postulate that the relationship between internal and external audit will evolve in the future so that the roles and responsibilities of internal audit will increase relative to external audit. New internal audit technologies, such as automated controls monitoring, will allow external auditors to place more reliance on the work of internal auditors. Some of this is already in place and being applied by external auditors,; such as internal journal entry analysis and audit assessments provided by internal auditors. If this trend continues, internal audit will ultimately have more responsibility than external audit regarding assurance on the quality of data for low-risk areas. However, high-risk areas must remain the responsibility of external audit because of independence issues. Ultimately, the American Institute of Certified Public Accountants (AICPA) will have to provide updated guidance concerning reliance on internal audit work by external auditors, and internal auditors have to be properly trained to meet these new challenges 
Frequency of externally audited financial statements, audit fees, and changing audit platform (Q8, Q9, Q10)

Participants debated the diminishing role of externally audited financial statements and the constant availability of externally audited financial statements due to real-time reporting and continuous reporting. "People are making individual types of decisions whether to invest or not invest, and the type of information they need to make decisions differs. A system designed from scratch would permit them to take a view of the information that's relevant to their decision problem instead of forcing everything into a one size fits all model. Ten years out infrastructure changes would be necessary to change the information paradigm that is in place. The only thing that prevents it from happening now and ten years from now is that the SEC and the AICPA and others have a vested interest in this one size fits all model" (P1).

There were varying opinions from participants regarding the audit fee model. If the same parties responsible for hiring the auditors remain responsible for agreeing and paying the audit fees, a bias will exist for either the company or the audit firm. The auditor will have an incentive to agree with the client in order to increase the likelihood of being fully compensated for current work and retained as the auditor in future engagements. This creates obvious problems relative to auditor independence and objectivity. It was suggested that the PCAOB either take on the responsibility of setting audit fees or handle the process of selecting company auditors in order to assist with ensuring that auditor independence is consistently maintained. This topic also relates to the potential for rolling the audit function into a general management monitoring and control platform. Within this framework, segregation of duties would need to be achieved to better prevent and deter decreased auditor professional skepticism. Furthermore, this would presumably enhance auditor independence and objectivity as well.

The main profile of services provided by large CPA firms in the future will incorporate forensics into the traditional audit, with an increase in revenue from this service. Assurance services will continue, but the nature of assurance will shift to an emphasis on real-time assurance via continuous auditing. Clients will require more risk-based services and wider forms of assurance services.

\section{Utilization of XBRL/GL, (Q11)}

There was an initial variation in responses which was mainly due to the lack of knowledge and confusion of XBRL/GL and its intended uses and capabilities. IT education must stem from the classroom, so that students gain the basic knowledge and skills necessary for performing in the field. Educators must account for XBRL/GL by both familiarizing students with the most current standard retrieval methodologies available, and allowing them to discover future tools later on in their careers.

In addition, participants noted that a common data model needs to be created across all ERP systems, so every general ledger ERP system knows the needed fields; such as, payment amount, date, payee, and payer. With the recent mandate from the Securities and Exchange Commission for public companies using XBRL for financial statements, the necessity for learning and training on XBRL/GL exists and needs to be addressed by companies as well as educational institutions. 


\section{CONCLUSIONS}

Expert consensus was reached relative to both the current state of audit and the future of audit over the next decade.

For a summary of highlights and recommendations resulting from both Delphi sessions, refer to Table 1.

\section{First Session}

- External auditors will rely more on internal audit work in the future

- Although use of automation will increase, judgment and decisionmaking cannot be automated

- The view of many of the topics would vary depending upon the evolution of the financial statements

- Audit will be cycled over the year, instead of only at year-end

- There is a need for a more global perspective

\section{Second Session}

- Client technology is leading audit procedures

- The use of technology depends upon proper safeguards for privacy (i.e. HIPAA)

- Automation can be used for more tedious tasks so that auditors can use their expert judgment for more pressing issues

Table 1 - Highlights and Recommendations Provided by Participants from the Delphi Method

Participants agreed that the audit model is currently incorporating continuous audits of business processes, and that auditors are using automation tools such as decision aids and risk assessment tools to assist with their audits. This will continue to evolve over the next decade as meta-analysis information exchanges with drill down capabilities will become more widely used for this purpose. Audit education has progressed and now increasingly incorporates the use of technology as well as offers new electives to help students better prepare for real-world audit. To keep up with technology, additional auditor technology training will be needed, especially for experienced auditors.

Over the next decade, the participants forecasted that technology will continue to be an important part of the audit process, but that it will not take over the judgment that is inherent in the auditing process. Judgment from audit experts will continue to be essential.

The participants also stated that the relationship between internal and external audit will continue to evolve with more responsibility shifting to the internal audit function. However, there was some debate as to whether the traditional audited financial statements will be replaced with more predictive, real-time statements. Although some participants noted that financial statements are competing with other forms of information, others felt that too many regulatory bodies are invested in the traditional model for it to significantly change. 
Participant responses during the brainstorming sessions validated the questions posed during the questionnaire rounds. Participants' insights during the brainstorming sessions related to the same areas of audit the Delphi addressed during both sessions.

Overall, results suggest it is not only likely, but necessary that the traditional audit undergoes changes to make it more relevant in this real-time economy. Auditing needs to stay in tune with continuous advancements in the profession in order to effectively meet the needs of the users of information.

\section{REFERENCES}

Anderson, U. (2012). Assurance Coordination: Managing the Organization's Assurance Network, presentation, 2/22/12.

Baldwin-Morgan, A. (1993). The impact of expert system audit tools on auditing firms in the year 2001: A Delphi investigation. Journal of Information Systems, 7(1), 16-34.

Bell, W. (1967). Technological forecasting - what it is and what it does. Management Review,56(8), 64.

Brancheau, J. C., Janz, B.D. \& Wetherbe, J.C. (1996). Key issues in information systems management: 1994-95 SIM Delphi results. MIS Quarterly, 20(2), 225-242.

Cegielski, C. G. (2008). Toward the development of an interdisciplinary information assurance curriculum: Knowledge domains and skill sets required of information assurance professionals. Decision Sciences Journal of Innovative Education, 6(1), 2949.

Chen, M. (2005). Ethics: An urgent competency in financial education. Journal of American Academy of Business, Cambridge, 6(2), 74-79.

Dalkey, N., \& Helmer, O. (1963). An experimental application of the Delphi method to the use of experts. Management Science, 9(3), 458-467.

Eilifsen, A., Knechel, R. \& Wallage, P. (2001). Application of the business risk audit model: A field study. Accounting Horizons, 15(3), 193-207.

Elliott, R. K. (1994). The future of audits. Journal of Accountancy, 178(3), 74-82.

Elliott, R. K. (1996). Auditing Reborn. CA Magazine, 129, 36-8.

Elliott, R. K. (2002). Twenty-first century assurance. Auditing, 21(1). 139.

Garsombke, H. \& Cerullo, M. (1984): Auditing advanced computer systems, The EDP Auditors Journal, 2(1): 1-11.

Holstrum, G.L.; Mock, T. J. \& West, R.N. (1986): The impact of technological events and trends on audit evidence in the year 2000: Phase I, Auditing Symposium VIII. Proceedings of the 1986 Touche Ross-- University of Kansas Symposium on Auditing Problems, Lawrence, KS: University of Kansas, 125-146.

Holstrum, G. L., T.J. Mock, \& West, R.N. (1988). The impact of technology on auditing: Moving into the 21st century. Institute of Internal Auditors Research Foundation, Altamonte Springs, Florida.

Humphrey, C., A. Loft, and M. Woods. (2009). The global audit profession and the international financial architecture: Understanding regulatory relationships at a time of financial crisis. Accounting, Organizations \& Society, 31(6/7), 810-825. 
Hunton, J. E., and J.M. Rose. (2010). 21st Century Auditing: Advancing Decision Support Systems to Achieve Continuous Auditing. Accounting Horizons, 24(2), 297312.

Mehr, R. I., and S. Neumann. (1970). Delphi forecasting project. Journal of Risk \& Insurance, 37(2), 241-246.

Melnyk, S. A., R.R. Lummus, R.J. Vokurka, L.J. Burns, and J. Sandor. (2009). Mapping the future of supply chain management: A Delphi study. International Journal of Production Research 47(16): 4629-4653.

Mock, T. J., P.R. Watkins, P. Caster, and K. Pincus. (1993). A review of the audit judgment symposium: 1983-1992. Auditing 12(2): 3.

Ogden, J. A., K.J. Petersen, J.R. Carter, and R.M. Monczka. (2005). Supply management strategies for the future: A Delphi study. Journal of Supply Chain Management: A Global Review of Purchasing \& Supply 41(3): 29-48.

Rowe, G., and G. Wright. (1999). The Delphi technique as a forecasting tool: Issues and analysis. International Journal of Forecasting 15(4): 353-375.

Singh, A. J. (2005). Future events and their impact on financial management in the US lodging industry: Delphi study to predict changes in 2007 and 2027. Journal of Retail \& Leisure Property 4(3): 236-254.

Vasarhelyi, M., R. Teeter, and J.P. Krahel. (2010). Audit Education and the Real-Time Economy. Issues in Accounting Education 25(3): 405-423.

Violino, B. (2004). You bought it, now audit. CFO 20(8): 17-19.

Worrell, J. L., Di Gangi, P. M., \& Bush, A. A. (2013). Exploring the use of the Delphi method in accounting information systems research. International Journal of Accounting Information Systems, 14(3), 193-208.

\section{APPENDIX 1 \\ QUESTIONS ASKED TO EXPERT PARTICIPANTS DURING THE BRAINSTORMING SESSIONS}

\section{First Delphi Meeting's Brainstorming session}

Non-audit opportunities (assurance services for CPAs that uses CPA competencies that has expanded the scope of provided services, e.g. provide independent continuous monitoring services)

E-Audit (Ways the audit service has been extended through electronic media e.g. perform large part of the audit remotely through video and voice and desktop sharing)

Audit automation (ways the audit has been automated, e.g. drive most of audit objective by data alarms)

Audit process (ways the way we audit has changed e.g. create automatic pinging)

\section{Second Delphi Meeting's Brainstorming Session}

Choose and rank five top technologies - most important to least important - used in audit.

How do you estimate the fee structure/base of billing? Please list issues and trends in what you see as the most important first. Please also specify the cause of any changes that have led to changing the fee structure.

How has the relationship changed between internal audit and external audit? 
How has accounting/auditing education changed to satisfy requirements of the new audit environment?

How has the litigation environment changed?

What are the main functions (profiles) of services being provided by the larger CPA firms and how do they interplay?

\section{APPENDIX 2 \\ QUESTIONS ASKED TO EXPERT PARTICIPANTS DURING THE DELPHI SESSIONS}

\section{First Delphi Meeting's Questionnaire Session}

What percentage of the external audit will be automated?

What percentage of the internal audit will be automated?

What will happen to usage of sampling techniques in auditing?

What will happen to usage of analytic procedures in auditing?

What will happen to audit judgment in auditing?

To what extent will internal auditors take over responsibility for the IT auditing now undertaken by the external auditor?

What is the likelihood that external auditors will offer opinions on financial statements more frequently than once a year?

What is the likelihood that a different model of auditor compensation will become prominent in practice?

What is the likelihood that inside the firm the audit function will be rolled into a general management monitoring and control platform?

What is the likelihood that XBRL-GL will emerge as the common platform for both reporting and assurance?

Assuming that eventually there will be continuous auditing, will there be more frequent reporting?

What is the likelihood that continuous assurance will be synonymous with auditing, as far as audit practice education is concerned?

\section{Second Delphi Meeting's Questionnaire Session}

What percentage of the external audit will be automated?

What percentage of the internal audit will be automated?

What will happen to usage of sampling techniques in auditing?

What will happen to usage of analytic procedures in auditing?

What will happen to human audit judgment in auditing?

To what extent will internal auditors take over the responsibility for the IT auditing which is currently undertaken by the external auditor?

To what extent will internal auditors take over the responsibility for financial auditing which is currently undertaken by the external auditor?

What is the likelihood that external auditors will offer opinions on financial statements more frequently?

What is the likelihood that a different model of audit fees will become prominent in practice?

What is the likelihood that inside the firm the audit function will be rolled into a general management monitoring and control platform?

What percentage of companies will utilize XBRL/ GL?

Assuming that eventually there will be some form of continuous auditing, will there be more frequent reporting? 